\title{
Effects of types and quantity of live food on growth performance and survival rate of cobia larvae (Rachycentron canadum)
}

\author{
Luong T. Le*, Nhan T. Dinh, Hoa T. B. Nguyen, Quyen T. T. Nguyen, \\ Trang T. N. Pham, \& Phu T. N. Nguyen \\ Falcuty of Fisheries, Nong Lam University, Ho Chi Minh City, Vietnam
}

\begin{abstract}
ARTICLE INFO
ABSTRACT

Research Paper

Received: January 11, 2019

Revised: April 16, 2019

Accepted: June 06, 2019

The objective of the study was to evaluate effects of 3 different diets and 3 different live food stocking densities on cobia fingerling rearing in composite tanks system in the Ninh Thuan $1^{\text {st }}$ grade Seafood Breeding Center from 6 - 25 days old. The experiment was performed as a $3 \times 3$ factorial design [live food types: $100 \%$ Copepoda (Cop), $100 \%$ Nauplius of Artemia (Art), and 50\% Copepoda $+50 \%$ Artemia; live food stocking densities: 5 - 10 individuals $/ \mathrm{mL}, 10-15$ individuals $/ \mathrm{mL}$, and $15-20$ individuals $/ \mathrm{mL}$. Each treatment had 5 replicates.

Keywords
Cobia
Cobia larvae
Live food
Rachycentron canadum

\section{${ }^{*}$ Corresponding author}

Le The Luong

Email: luong.lethe@hcmuaf.edu.vn

After the nursery phase, the results showed that environmental parameters in all treatments were in normal ranges for cobia larvae growth. There was no difference in total length when cobia larvae were fed different feed densities $(P<0.05)$. The $100 \%$ Art live food and the live food density of $15-20$ individuals/mL gave the highest growth rate, whereas the $100 \%$ Cop live food and the live food density of $5-10$ individuals $/ \mathrm{mL}$ resulted in the lowest weight of larvae. There was no difference in weight gain when simultaneously changing the types and live food density $(P<0.05)$. The survival rate of cobia larvae was highest for the $100 \%$ Cop live food and the live food density of 15 - 20 individuals $/ \mathrm{mL}$ and lowest for the $100 \%$ Art live food and the live food density of $5-10$ individuals $/ \mathrm{mL}$. However, there was no difference in the survival rate of cobia larvae when simultaneously changing the types and live food density $(P<$ $0.05)$.
\end{abstract}

Cited as: Le, L. T., Dinh, N. T., Nguyen, H. T. B., Nguyen, Q. T. T., Pham, T. N., \& Nguyen, P. T. N. (2019). Effects of types and quantity of live food on growth performance and survival rate of cobia larvae (Rachycentron canadum). The Journal of Agriculture and Development 18(4), 42-50. 


\title{
Nghiên cứu ảnh hưởng của loại và lượng thức ăn sống lên tốc độ sinh trưởng và tỷ lệ sống của ấu trùng cá bớp (Rachycentron canadum)
}

\author{
Lê Thế Lương*, Đinh Thế Nhân, Nguyễn Thị Bích Hòa, Nguyễn Thị Thu Quyên, Phạm Thị \\ Ngọc Trang \& Nguyễn Thị Ngọc Phú
}

Khoa Thủy Sản, Trường Đại Học Nông Lâm TP.HCM, TP. Hồ Chí Minh

\author{
THÔNG TIN BÀI BÁO \\ Bài báo khoa học \\ Ngày nhận: 11/01/2019 \\ Ngày chỉnh sửa: 16/04/2019 \\ Ngày chấp nhận: 06/06/2019

\section{Từ khóa} \\ Ấu trùng cá bớp \\ Cá bớp \\ Rachycentron canadum \\ Thức ăn sống

\section{*Tác giả liên hệ} \\ Lê Thế Lương \\ Email: luong.lethe@hcmuaf.edu.vn
}

\section{TÓM TẮT}

Mục tiêu của nghiên cứu nhằm đánh giá ảnh hưởng của 3 loại thức ăn và 3 mật độ thức ăn khác nhau đến việc ương ấu trùng cá bớp trong hệ thống bể composite tại Trung tâm Giống hải sản cấp I Ninh Thuận giai đoạn từ 6 - 25 ngày tuổi. Thí nghiệm được thực hiện theo kiểu 2 nhân tố $3 \times 3$ [loại thức ăn: 100\% Copepoda (Cop), $100 \%$ Nauplius của Artemia (Art) và $50 \%$ Copepoda $+50 \%$ Nauplius của Artemia; mật độ thức ăn: 5 - $10 \mathrm{con} / \mathrm{mL}, 10-15 \mathrm{con} / \mathrm{mL}$ và $15-20$ $\mathrm{con} / \mathrm{mL}$ ]. Mỗi nghiệm thức được lặp lại 5 lần.

Kết quả sau đợt ương cho thấy các chỉ tiêu về môi trường trong các nghiệm thức đều được giữ ổn định trong khoảng thích hợp cho sự phát triển của ấu trùng cá bớp. Không có sự khác biệt tăng trưởng về chiều dài khi ấu trùng cá bớp ăn các loại thức ăn với các mật độ thức ăn khác nhau $(P<0,05)$. Loại thức ăn $100 \%$ Art và lượng thức ăn 15 - 20 con/mL cho tăng trưởng cao nhất, trong khi loại thức ăn $100 \%$ Cop và lượng thức ăn 5 - 10 con $/ \mathrm{mL}$ cho trọng lượng thấp nhất. Không có sự khác biệt tăng trưởng về trọng lượng khi thay đổi đồng thời loại và lượng thức ăn $(P<0,05)$. Tỉ lệ sống ấu trùng cá bớp cao nhất ở loại thức ăn $100 \%$ Cop và lượng thức ăn 15 - 20 con $/ \mathrm{mL}$ và thấp nhất ở loại thức ăn $100 \%$ Art và lượng thức ăn 5 $10 \mathrm{con} / \mathrm{mL}$. Tuy nhiên, khi thay đổi đồng thời loại và lượng thức ăn sống thì không có sự khác biệt về tỉ lệ sống $(P<0,05)$.

\section{1. Đặt Vấn Đề}

Cá bớp (Rachycentron canadum Linnaeus, 1766) là một trong những loài cá biển có sự phân bố rộng (Liao \& ctv., 2004; Holt \& ctv., 2007; Nguyen \& ctv., 2008), có giá trị về kinh tế và có thị trường tiêu thụ rộng lớn. Tuy nhiên, lượng cá khai thác trong tự nhiên ngày càng ít dần đi (Nguyen, 2016). Do đó, để đáp ứng nhu cầu tiêu dùng, người ta đã tiến hành nuôi thương phẩm loài cá này với quy mô lớn. Giống là một khâu rất quan trọng trong chuỗi sản xuất, có ý nghĩa rất lớn quyết định sự thành công của vụ nuôi. Trước đây, giống cá giò chủ yếu là khai thác ngoài tự nhiên, do đó có số lượng ít, kích thước cá không đồng đều, thường bị xây xát do đánh bắt dẫn đến chất lượng giống không đảm bảo cũng như việc thả giống không chủ động (Dang, 2017). Do đó, việc nghiên cứu sản xuất giống cá bớp nhân tạo trên thế giới (Nancy \& ctv., 2001) nói chung và ở Việt Nam nói riêng được quan tâm từ rất sớm. Ở Việt Nam hiện có một số cơ sở đang sản xuất ấu trùng cá bớp, tuy nhiên tỷ lệ sống của cá còn thấp (khoảng $3-5 \%$ ) vì chưa có qui trình và chế độ cho ăn thích hợp (Nguyen, 2016). Chính vì vậy, việc thử nghiệm các khẩu phần thức ăn sống khác nhau trong qui trình ương nuôi để tìm ra khẩu phần và chế độ cho ăn tối ưu là rất cần thiết để góp phần nâng cao tỉ lệ sống, giảm chi phí sản xuất cũng như tăng tính ổn định, đáp ứng nhu cầu về con giống.

\section{Vật Liệu và Phương Pháp Nghiên Cứu}

\section{1. Đối tượng nghiên cứu}

Cá bớp (Rachycentron canadum Linnaeus, 1766) giai đoạn từ 6 đến 25 ngày tuổi. 


\subsection{Thời gian và địa điểm nghiên cứu}

Nghiên cứu được thực hiện tại Trung tâm Giống hải sản cấp I Ninh Thuận, xã An Hải, huyện Ninh Phước, tỉnh Ninh Thuận, từ tháng 4 đến tháng 9 năm 2016.

\subsection{Nguồn cá thí nghiệm}

Cá được chọn từ cùng một đợt đẻ của một cặp cá bố mẹ, sau khi nở 2 ngày tuổi, noãn hoàn tiêu biến, cá được cho ăn bằng thức ăn có thành phần $50 \%$ Cop $+50 \%$ Rotifer (Rot) với mật độ thức ăn $15-20$ con $/ \mathrm{mL}$ cho đến khi cá đạt 5 ngày tuổi. Tiếp tục sử dụng nguồn cá này để thực hiện các thí nghiệm tiếp theo.

\subsection{Nguồn nước thí nghiệm}

Nước mặn được bơm trực tiếp từ biển vào hệ thống bể lọc thô qua tầng lọc ngược xuống bể chứa lắng. Tại đây xử lý chlorine với nồng độ 30 ppm sục khí mạnh trong vòng 48 giờ. Sau đó tiến hành kiểm tra nước có còn dư lượng chlorine không. Nếu không còn dư lượng chlorine thì được sử dụng cho các công đoạn tiếp theo.

Nguồn nước ngọt: Lấy từ nước máy và nước giếng ngầm. Lắng lọc qua lắng lọc của trại.

Nguồn nước lợ (32\%o-33\%o) bố trí thí nghiệm được pha từ hai nguồn nước trên.

\subsection{Bố trí thí nghiệm}

Thí nghiệm xác định sự ảnh hưởng của 2 nhân tố loại và lượng thức ăn được thực hiện với 9 nghiệm thức là tổ hợp của 3 loại thức ăn $(100 \%$ Cop, $100 \%$ Art và $50 \% \mathrm{Cop}+50 \%$ Art) và 3 mật độ thức ăn khác nhau (5 - 10 con/mL, 10 $15 \mathrm{con} / \mathrm{mL}$ và $15-20 \mathrm{con} / \mathrm{mL})$. Mỗi nghiệm thức được thực hiện với 5 lần lạ̣p lại tại cùng thời điểm, tổng cộng có 45 lô thí nghiệm. Thể tích mỗi bể là 100 L. Cá bớp trong các nghiệm thức thí nghiệm được thả với mật độ 5 con/L.

\subsection{Quá trình chăm sóc cá}

Cá thí nghiệm được cho ăn 4 lần/ngày vào lúc $6,10,14$, và 17 giờ. Trước khi cho âu trùng cá ăn thì làm giàu luân trùng 100 ppm (Dùng $10 \mathrm{~g}$ Selco S.parkle $\approx 100 \mathrm{ppm}$ cho vào máy xay sinh tố, xay nhuyễn rồi cho vào thùng chứa 100 lít nước) trước 6 - 12 giờ. Siphon thức ăn thừa, vệ sinh dây sục khí, bổ sung nước vào hệ thống thí nghiệm để bù lượng nước thất thoát do siphon, hằng ngày kiểm tra cá, vớt bọt.

Thay nước: Thay 20\% lượng nước mới mỗi ngày.

Môi trường: Các yếu tố môi trường như độ mặn, pH, nhiệt độ, lượng oxy hòa tan được theo dõi hàng ngày và duy trì ổn định trong suốt quá trình thí nghiệm.

\subsection{Phương pháp thu thập và xử lý số liệu}

2.7.1. Các thông số môi trường trong hệ thống thí nghiệm

Các yếu tố môi trường trong hệ thống thí nghiệm được đo đạc hàng ngày và duy trì trong phạm vi thích hợp với sự tăng trưởng và phát triển của ấu trùng cá bớp (Nguyen, 1998; Nguyen, 2002; Liao \& ctv., 2003) với tần suất 2 lần/ngày vào lúc 9 giờ sáng và 3 giờ chiều bằng cách đo nhiệt độ nước bằng nhiệt kế thủy ngân, hàm lượng $\mathrm{oxy}$ hòa tan bằng máy đo $\mathrm{DO}$ và $\mathrm{pH}$ bằng máy đo $\mathrm{pH}$. Riêng hai chỉ tiêu hàm lượng $\mathrm{N}^{-\mathrm{NH}_{3}}$ (đo bằng test kit) và độ mặn (đo bằng khúc xạ kế 0 - 100\%o) được đo với tuần suất 1 lần/tuần.

\subsubsection{Phương pháp xác định các chỉ tiêu sinh trưởng}

Cá trong các nghiệm thức thí nghiệm được cân, đo, đếm mỗi tuần một lần, sau khi cân đo thì cá được thả lại bể ương. Các chỉ tiêu được xác định như sau:

Xác định tốc độ tăng trưởng tương đối: Dùng vợt vớt cá cho lên lam kính, sau đó dùng giấy thấm nước cho cá khô rồi sử dụng dụng cụ gắp cá cho vào cân điện tử 4 số lẻ để cân cá.

Xác định tốc độ tăng trưởng tuyệt đối về chiều dài: Dùng vợt vớt cá cho lên lam kính, sau đó dùng kính hiển vi có trắc vi thị kính, và có kết nối với máy tính chuyên dụng cho phòng thí nghiệm để đo chiều dài cá.

\subsubsection{Xác định các thông số và công thức tính}

Cá trong các lô thí nghiệm được kiểm tra tình trạng sức khỏe hàng ngày, định kì cân, đo cá 1 tuần/lần, xác định tỉ lệ sống, tăng trưởng về chiều dài tổng và trọng lượng của cá ở các lô thí nghiệm. Các chỉ tiêu nghiên cứu đều được xác định theo phương pháp thường quy thường sử dụng trong nghiên cứu nuôi trồng thủy sản. Cụ thề:

Tốc độ tăng trưởng tuyệt đối (g/ngày): 


$$
\mathrm{GR}=\frac{\mathrm{W}_{2}-\mathrm{W}_{1}}{\mathrm{t}_{2}-\mathrm{t}_{1}}
$$

Tốc độ tăng trưởng tương đối (\%/ ngày):

$$
\mathrm{SGR}=\frac{\mathrm{LnW}_{2}-\mathrm{LnW}_{1}}{\mathrm{t}_{2}-\mathrm{t}_{1}} \times 100
$$

$\mathrm{W}_{1}$ : Khối lượng cá ở thời điểm $\mathrm{t}_{1}$

$\mathrm{W}_{2}$ : Khối lượng cá ở thời điểm $\mathrm{t}_{2}$

Tốc độ tăng trưởng tuyệt đối về chiều dài:

$$
\mathrm{TL}=\frac{\mathrm{L}_{1}-\mathrm{L}_{0}}{\mathrm{t}_{1}-\mathrm{t}_{0}}
$$

$\mathrm{L}_{0}$ : Chiều dài thân đo ở thời điểm $\mathrm{T}_{0}$

$\mathrm{L}_{1}$ : Chiều dài thân đo ở thời điểm $\mathrm{T}_{1}$

Tỉ lệ sống (\%) được tính theo công thức:

$$
\mathrm{TLS}=\frac{\mathrm{X}}{\mathrm{Y}} \times 100
$$

X: Số cá tại thời điểm kết thúc thí nghiệm

Y: Số cá thể ban đầu

\subsubsection{Phương pháp xử lý số liệu}

Số liệu được xử lý dựa trên 2 nhân tố là loại và lượng thức ăn bằng cách sử dụng phần mềm MS Excel nhập và xử lý số liệu. Trước khi tiến hành phân tích thống kê, số liệu phần trăm (\%) tỷ lệ sống được chuyển dạng bằng arcsin. Phân tích thống kê bằng phương sai hai yếu tố mẫu đo lường lặp lại (repeated ANOVA) với các nghiệm thức (loại và lượng thức ăn) là yếu tố chính và thời gian (đợt thu mẫu) là yếu tố đo lường lặp lại. Kiểm định khác biệt nhỏ nhất có ý nghĩa (least significant difference, LSD) được dùng để so sánh sự khác biệt giữa các mức của yếu tố thí nghiệm. Mức xác suất $P<0,05$ được chấp nhận như tiêu chuẩn đánh giá sự khác biệt có ý nghĩa thống kê. Tất cả các phân tích thống kê được thực hiện bằng phần mềm IBM SPSS Statistics version 19.0.

\section{Kết Quả và Thảo Luận}

\subsection{Giá trị các yếu tố môi trường trong quá trình thí nghiệm}

Trong quá trình thí nghiệm, các chỉ tiêu về môi trường được duy trì một cách tối ưu cho điều kiện sống của ấu trùng cá bớp (Nguyen, 1998; Nguyen, 
2002; Liao \& ctv., 2003). Giá trị cụ thể các thông số môi trường và kết quả phân tích phương sai của chúng được thể hiện qua Bảng 1 .

Qua Bảng 1 ta thấy, giá trị các yếu tố môi trường chỉ dao động trong một khoảng rất nhỏ và chênh nhau không nhiều giữa các lần đo sáng và chiều. Độ mặn trung bình chỉ dao động trong khoảng 32,47 - 32,58\%o. Lượng oxy hòa tan trung bình dao động từ $4,52-4,57 \mathrm{mg} / \mathrm{L}$ vào buổi sáng và $4,84-4,89 \mathrm{mg} / \mathrm{L}$ vào buổi chiều. Nhiệt độ trung bình dao dộng trong khoảng 28,03 $28,43^{0} \mathrm{C}$ và $\mathrm{pH}$ dao động trong khoảng $8,22-8,47$, mức dao động $\mathrm{pH}$ giữa sáng và chiều chỉ đạt tối đa 0,13 và tối thiểu là 0,02 . Riêng chỉ tiêu $\mathrm{N}-\mathrm{NH} 3$ đo được trong giai đoạn này có giá trị bằng không, nghĩa là trong giai đoạn này trong bể ương chưa tồn tại $\mathrm{N}-\mathrm{NH}_{3}$. Sự thay đổi của các yếu tố môi trường này đều phù hợp với điều kiện sinh trưởng và phát triển bình thường của ấu trùng cá bớp.

\subsection{Tăng trưởng về chiều dài của ấu trùng cá bớp}

Tăng trưởng về chiều dài của ấu trùng cá bớp giai đoạn 6 - 25 ngày tuổi được định kì đo đạc, xử lý và phân tích số liệu. Tăng trưởng về khối lượng ấu trùng cá bớp ở các nghiệm thức thí nghiệm được thể hiện ở Bảng 2.

Trong 2 tuần đầu thí nghiệm, giai đoạn này ấu trùng cá bớp tăng trưởng chậm, ở cả 3 loại thức ăn và 3 mật độ thức ăn đều có mức tăng trưởng tương đương về chiều dài. Bắt đầu từ tuần thứ 3 trở đi, ấu trùng cá bớp tăng trưởng nhanh ở tất cả các nghiệm thức thí nghiệm (Hình 1). Ở tuần thứ 3, ở mật độ thức ăn 10 - 15 con/mL, loại thức ăn có thành phần $100 \%$ Cop cho mức tăng trưởng về chiều dài cao hơn so với loại thức ăn $100 \%$ Art và $50 \% \mathrm{Cop}+50 \%$ Art. Ở mật độ thức ăn 15 - $20 \mathrm{con} / \mathrm{mL}$, loại thức ăn có thành phần $100 \%$ Cop cho mức tăng trưởng về chiều dài cao nhất, loại thức ăn 50\% Cop + 50\% Art cho mức tăng trưởng trung bình, và loại thức ăn $100 \%$ Art cho mức tăng trưởng thấp nhất. Tuy nhiên, sự khác biệt về chiều dài tổng khi cho ấu trùng cá bớp ăn 3 loại thức ăn khác nhau với 3 mật độ thức ăn khác nhau không có ý nghĩa về mặt thống kê $(P<0,05)$. Khi thay đổi đồng thời loại và lượng thức ăn sống thì sự tác động đồng thời lên tăng trưởng về chiều dài ấu trùng cá bớp không khác biệt có ý nghĩa về mặt thống kê $(P<0,05)$.

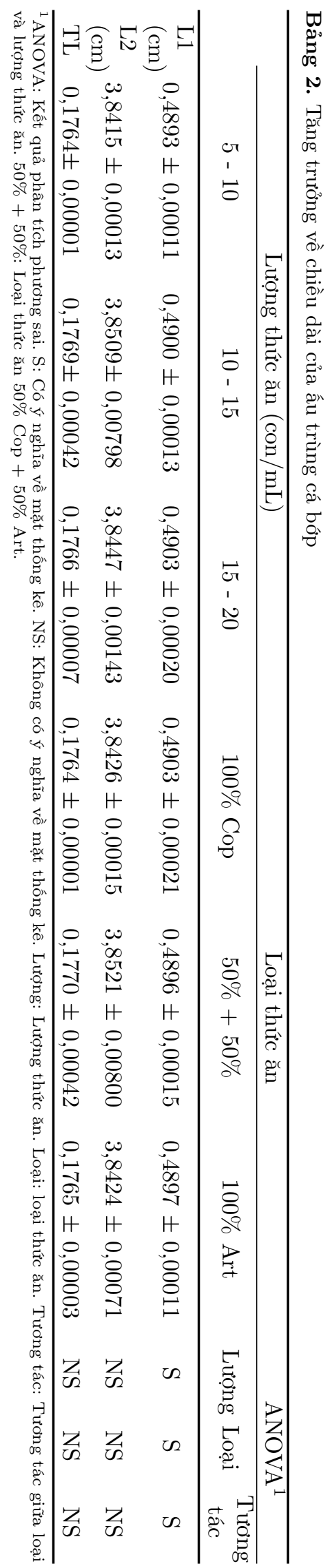

www.jad.hcmuaf.edu.vn 


\subsection{Tăng trưởng về trọng lượng của ấu trùng cá bớp}

Tương tự như tăng trưởng về chiều dài, trọng lượng ấu trùng cá bớp trong hai tuần đầu thí nghiệm tăng trưởng rất chậm. Kể từ tuần thứ 3 , trọng lượng của ấu trùng cá bớp tăng lên rất nhanh. Tăng trưởng về trọng lượng ấu trùng cá bớp được thể hiện qua Bảng 3.

Qua Bảng 3 ta thấy, trong 3 loại thức ăn, ấu trùng cá bớp có mức tăng trưởng về trọng lượng cao nhất ở nghiệm thức thức ăn $100 \%$ Art với trọng lượng cuối đạt $0,1559 \pm 0,00128 \mathrm{~g}$, tăng trưởng tuyệt đối bằng $0,0065 \pm 0,00007 \mathrm{~g} /$ ngày và tăng trưởng chuyên biệt ngày đạt $8,2007 \pm$ $0,04031 \%$ và thấp nhất ở nghiệm thức thức ăn $100 \%$ Cop với trọng lượng cuối 0,1528 \pm 0,00004 $\mathrm{g}$, tăng trưởng tuyệt đối bằng $0,0063 \pm 0,00000$ g/ngày và tăng trưởng chuyên biệt ngày đạt $8,0494 \pm 0,01506 \%$. Sự khác nhau về trọng lượng âu trùng cá ở các loại thức ăn khác nhau có ý nghĩa về mặt thống kê $(P<0,05)$.

Với 3 mật độ thức ăn, mật độ thức ăn 15 $20 \mathrm{con} / \mathrm{mL}$ cho mức tăng trưởng về trọng lượng cao nhất với trọng lượng cuối là $0,1555 \pm 0,00116$ $\mathrm{g}$, tăng trưởng tuyệt đối bằng $0,0064 \pm 0,00006$ gam/ngày và tăng trưởng chuyên biệt ngày đạt $8,1488 \pm 0,04177 \%$ và thấp nhất ở nghiệm thức mật độ thức ăn 5 - 10 con $/ \mathrm{mL}$ với trọng lượng cuối là $0,1525 \pm 0,00005 \mathrm{~g}$, tăng trưởng tuyệt đối bằng $0,0063 \pm 0,00000 \mathrm{~g} /$ ngày và tăng trưởng chuyên biệt ngày đạt $8,1071 \pm 0,00604 \%$. Sự khác nhau về trọng lượng ấu trùng cá ở các mật độ thức ăn khác nhau có ý nghĩa về mặt thống kê $(P<0,05)$.

Trong 3 tuần thí nghiệm, ở mật độ thức ăn 10 - 15 con/mL, loại thức ăn có thành phần $100 \%$ Cop cho mức tăng trưởng về chiều dài cao hơn so với loại thức ăn $100 \%$ Art và $50 \%$ Cop $+50 \%$ Art. Ở mật độ thức ăn 15 - 20 con/mL, loại thức ăn có thành phần $100 \%$ Cop cho mức tăng trưởng về chiều dài cao nhất, loại thức ăn $50 \%$ Cop + $50 \%$ Art cho mức tăng trưởng trung bình, và loại thức ăn $100 \%$ Art và cho mức tăng trưởng thấp nhất về chiều dài. Mật độ thức ăn $5-10 \mathrm{con} / \mathrm{mL}$ cho mức tăng trưởng tương đương nhau ở cả 3 loại thức ăn (Hình 2). Tuy nhiên, khi thay đổi đồng thời loại và lượng thức ăn thì không có sự khác biệt có ý nghĩa về mặt thống kê về trọng lượng ấu trùng cá bớp $(P<0,05)$.

Sự khác nhau về lượng thức ăn đối với mức tăng trưởng tuyệt đối và sự phát triển chuyên

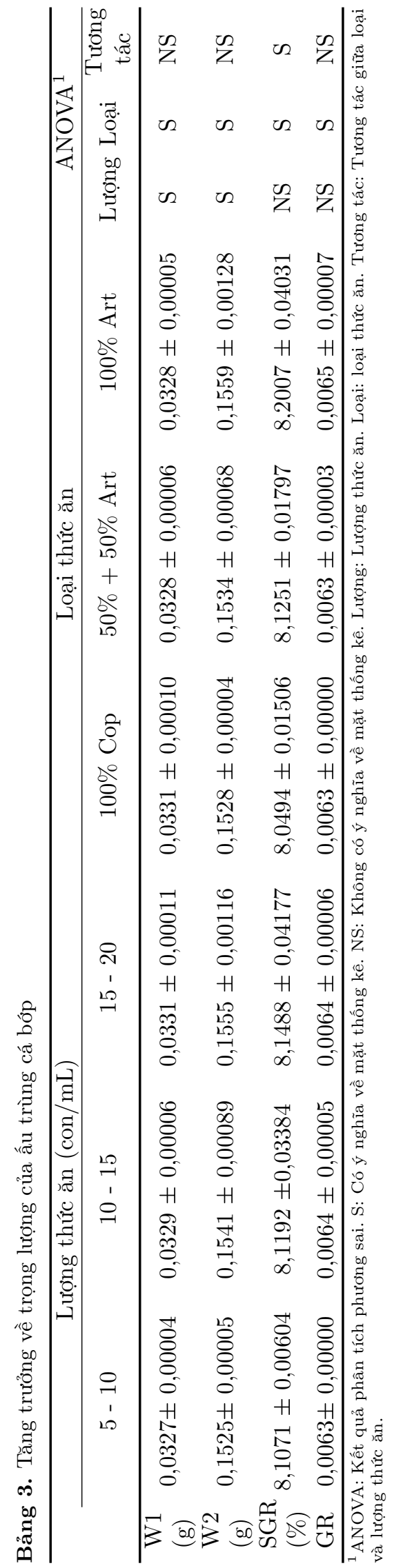



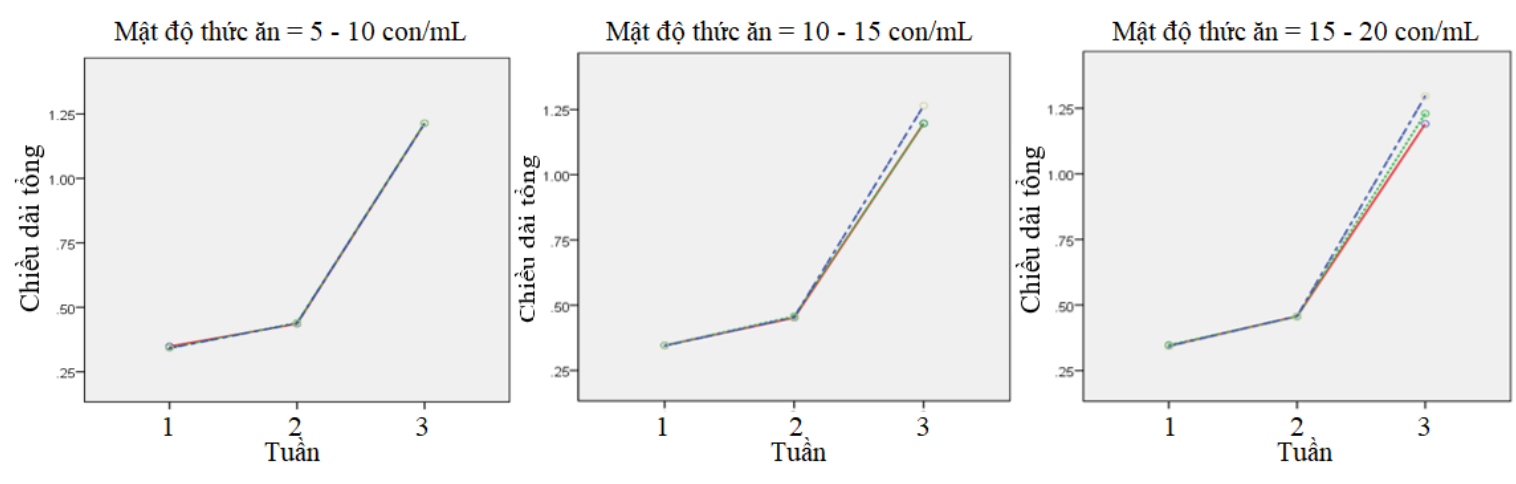

$-100 \%$ Cop

- - 50\% Copepod+ $50 \%$ Art

-.-.- 100 Art

Hình 1. Chiều dài tổng của ấu trùng cá bớp qua các tuần thí nghiệm.
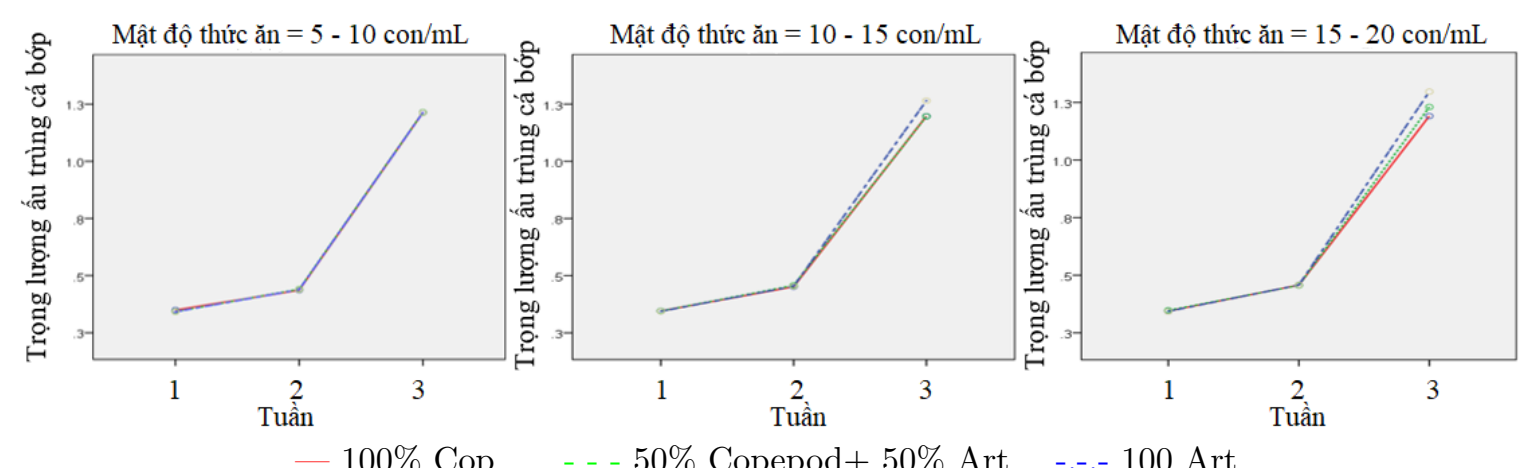

$-100 \%$ Cop

- - $50 \%$ Copepod $+50 \%$ Art

-.-.- 100 Art

Hình 2. Trọng lượng của ấu trùng cá bớp qua các tuần thí nghiệm.
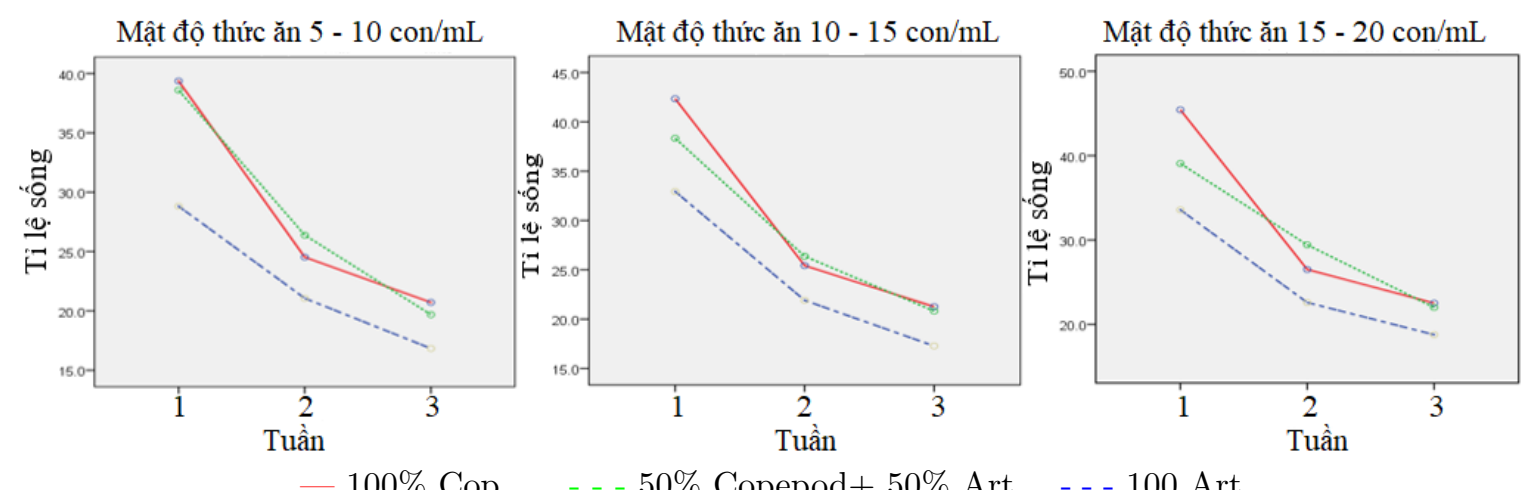

$-100 \%$ Cop

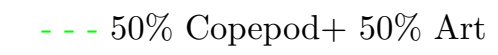

-.-.- 100 Art

Hình 3. Tỉ lệ sống của ấu trùng cá bớp qua các tuần thí nghiệm.

biệt ngày không có ý nghĩa về mặt thống kê $(P$ $<0,05)$. Sự khác nhau giữa các loại thức ăn có ảnh hưởng đến tăng trưởng tương đối và tăng trưởng chuyên biệt ngày có ý nghĩa về mặt thống kê $(P<0,05)$. Nếu thay đổi đồng thời loại và lượng thức ăn thì có ảnh hưởng đến tăng trưởng chuyên biệt ngày có ý nghĩa về mặt thống kê $(P$ $<0,05)$. Tuy nhiên, thay đổi đồng thời loại và lượng thức ăn thì sự ảnh hưởng đến tăng trưởng tuyệt đối không có ý nghĩa về mặt thống kê $(P$ $<0,05)$.

Điều đó cho thấy, khi ấu trùng cá bớp có sự tăng trưởng về khối lượng thì cần lượng thức ăn nhiều hơn. Nói cách khác, cho ấu trùng cá bớp ăn đầy đủ hơn sẽ cho mức tăng trưởng tốt hơn. 
So sánh kết quả về ảnh hưởng của loại và lượng thức ăn tươi sống đến tăng trưởng của ấu trùng cá bớp giai đoạn 6 - 25 ngày tuổi trong nghiên cứu này với nghiên cứu của Đặng Văn Hiệp \& ctv. (2017), ta thấy hai nghiên cứu có kết quả tương tự nhau và phù hợp với thực tiễn sản xuất thực tế tại Trung tâm giống Hải sản cấp I Ninh Thuận cũng như tại các trại sản xuất ương nuôi cá bớp tại địa phương.

\subsection{Tỉ lệ sống của ấu trùng cá bớp}

Nhìn chung, trong suốt quá trình thí nghiệm, dù sử dụng loại thức ăn nào và cho ăn với lượng thức ăn như thế nào thì tỉ lệ sống đều có xu hướng giảm dần theo thời gian. Tỉ lệ sống của ấu trùng cá bớp được thể hiện qua Bảng 4 .

Tỉ lệ sống của ấu trùng cá bớp có sự khác nhau rõ rệt khi cho ấu trùng cá ăn các loại thức ăn khác nhau. Trong 3 loại thức ăn, ấu trùng cá ăn thức ăn có thành phần $100 \%$ Cop có tỉ lệ sống giảm nhiều nhất nhưng vẫn đạt mức cao nhất với 13,5 土 0,34\%, 2 nghiệm thức thức ăn còn lại $(100 \%$ Art và $50 \%$ Cop $+50 \%$ Art) có tỉ lệ sống tương đương nhau. Sự khác nhau về tỉ lệ sống khi cho ấu trùng cá bớp ăn các loại thức ăn khác nhau có ý nghĩa về mặt thống kê $(P<0,05)$.

Trong các mật độ thức ăn, mật độ 15 - 20 con $/ \mathrm{mL}$ cho tỉ lệ sống cao nhất với $14,7 \pm 0,58 \%$ khi cho ấu trùng cá ăn thức ăn có thành phần $50 \%$ Cop $+50 \%$ Art; $14,0 \pm 0,20 \%$ khi cho âu trùng cá ăn thức ăn có thành phần $100 \%$ Cop và $10,4 \pm 0,25 \%$ khi cho ấu trùng cá ăn thức ăn có thành phần $100 \%$ Art. Mật độ thức ăn 5 - 10 con $/ \mathrm{mL}$ cho tỉ lệ sống thấp nhất với tỉ lệ sống là $8,4 \pm 0,38 \%$ khi cho ấu trùng cá ăn thức ăn có thành phần $100 \%$ Art; $11,4 \pm 0,35 \%$ khi cho ấu trùng cá ăn thức ăn có thành phần $100 \%$ Cop và $12,5 \pm 0,38 \%$ khi cho ấu trùng cá ăn thức ăn có thành phần $50 \%$ Cop + 50\% Art. Mật độ thức ăn $10-15 \mathrm{con} / \mathrm{mL}$ cho tỉ lệ sống ở mức trung bình (Hình 3). Sự khác nhau về tỉ lệ sống khi cho ấu trùng cá bớp ăn các lượng thức ăn khác nhau có ý nghĩa về mặt thống kê $(P<0,05)$. Tuy nhiên, khi thay đổi đồng thời loại và lượng thức ăn thì sự tác động lên tỉ lệ sống ấu trùng cá bớp không có ý nghĩa về mặt thống kê $(P<0,05)$.

Như vậy, dù cho ăn loại thức ăn tươi sống nào đi nữa thì mật độ thức ăn $15-20 \mathrm{con} / \mathrm{mL}$ vẫn có tỉ lệ sống cao nhất và mật độ thức ăn $5-10$ con $/ \mathrm{mL}$ có tỉ lệ sống thấp nhất. Nghiệm thức thức ăn 10 $15 \mathrm{con} / \mathrm{mL}$ cho tỉ lệ sống ở mức trung bình so với 
2 nghiệm thức còn lại. Kết quả tỷ lệ sống của cá đạt được trong nghiên cứu này phù hợp với kết quả nghiên cứu của Dang (2017) và Tran \& ctv. (2013).

\section{Kết Luận}

Không có sự khác biệt tăng trưởng về chiều dài khi cho ấu trùng cá bớp giai đoạn 6 - 25 ngày tuổi ăn các loại thức ăn với các mật độ thức ăn khác nhau. Các loại và lượng thức ăn khác nhau cho sự tăng trưởng khác nhau về trọng lượng, loại thức ăn có thành phần $100 \%$ Art và mật độ thức ăn $15-20 \mathrm{con} / \mathrm{mL}$ cho mức tăng trưởng cao nhất về trọng lượng và loại thức ăn $100 \%$ Cop và lượng thức ăn 5 - 10 con $/ \mathrm{mL}$ cho mức tăng trưởng về trọng lượng thấp nhất. Tuy nhiên, khi thay dổi đồng thời loại và lượng thức ăn sống thì không có sự khác biệt về tăng trưởng về trọng lượng.

Loại và lượng thức ăn sống có ảnh hưởng đến tỉ lệ sống của ấu trùng cá bớp giai đoạn 6 - 25 ngày tuổi. Tỉ lệ sống của ấu trùng cá bớp cao nhất ở mật độ 15 - 20 con/mL và thấp nhất ở mật độ thức ăn $5-10$ con $/ \mathrm{mL}$. Ấu trùng cá bớp ăn các loại thức ăn khác nhau có tỉ lệ sống khác nhau. Loại thức ăn 100\% Cop cho tỉ lệ sống cao nhất và $100 \%$ Art cho tỉ lệ sống thấp nhất. Tuy nhiên, khi thay đổi đồng thời loại và lượng thức ăn sống thì không có sự khác biệt về tỉ lệ sống của chúng.

Do vậy, mật độ thức ăn $15-20$ con/mL là tốt nhất và mật độ thức ăn $5-10 \mathrm{con} / \mathrm{mL}$ là kém nhất cho sự phát triển của ấu trùng cá bớp. Trong các loại thức ăn, loại thức ăn có thành phần $100 \%$ Art cho kết quả cao nhất và loại thức ăn có thành phần 100\% Cop cho kết quả kém nhất về sự phát triển của ấu trùng cá bớp giai đoạn 6 - 25 ngày tuổi. Tuy nhiên, cần tính toán chi phí và cách thức cho ăn hợp lý cho từng giai đoạn phát triển của ấu trùng cá để đạt hiệu quả cao nhất.

\section{Tài Liệu Tham Khảo (References)}

Dang, H. V. (2017). Effects of live food types on growth performance and survivability of cobia Rachycentron Canadum (Linnaeus, 1766) from 2 to 25 days of age in Ninh Thuan. (Unpublished master's thesis). Nha Trang Univetsity, Nha Trang, Vietnam.
Holt, G. J., Faulk, C. K., \& Schwarz, M. H. (2007). A review of the larviculture of cobia Rachycentron canadum, a warm water marine fish. Aquaculture 268(1-4), 181-187.

Liao, I. C., Huang, T. S., Tsai, W. S., Hsueh, C. M., \& Chang, S. L. (2004). Cobia culture in Taiwan: current status and problems. Aquaculture 237(1-4), 155-165.

Liao, I. C., Su, H. M., \& Chang, E. Y. ( 2001). Techniques in finfish larviculture in Taiwan. Aquaculture 200(1-2), $1-31$.

Nancy, J. B., Robin, M. O., Jeffrey, M. L., James, S. F., \& Karen, M. B. (2001). Reproductive biology of cobia, Rachycentron canadum, from coastal waters of the southern United States. Fishery Bulletin 99(1), 1528.

Nguyen, C., Nguyen, C. V., Nguyen, D. H., Dao, H. T., Nguyen, P. H., Dao, S. M., Nguyen, T. C., Pham, N. T., Nguyen, T. T. X., \& Pham, T. (2002). List of marine and brackish water species in Vietnam. Ha Noi, Vietnam: DANIDA- Ministry of Fisheries (SUMA Project).

Nguyen, L. M. (2016). Current status of hatchery production and copia farming in Vietnam. (Unpublished master's thesis). Nong Lam University, Ho Chi Minh City, Vietnam.

Nguyen, M. D. (1998). Biological basis of some economic fish species in coastal areas in the South Central Coast serving for the protection and development of resources. (Unpublished doctoral dissertation). Institute of Oceanography, Nha Trang, Vietnam.

Nguyen, Q. H., Sveier, H., Bui, V. H., Le, A. T., Nhu, V. C., Tran, M. T., \& Svennevig, N. (2008). Growth performance of cobia, Rachycentron canadum, in sea cages using extruded fish feed or trash fish. In: Yang, Y., Vu, X. Z., \& Zhou, Y. Q. (Eds.). Cage Aquaculture in Asia: Proceedings of The Second International Symposium on Cage Aquaculture in Asia (42-47). Asian Fishery Society/Zhejang University, Manila/China.

Tran, H. N., Dang, H. K., Tran, K. D., \& Le, V. Q. (2013). Rearing cobia (Rachycentron canadum) larvae with different diets. Can Tho University Journal of Science 25, 43-49. 